\title{
Use of hemodialysis for dabigatran clearance in a patient requiring urgent surgery. A case report
}

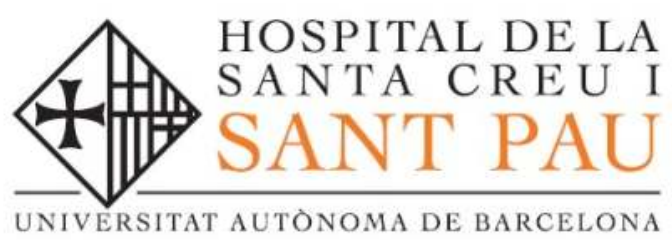

\section{Diaz Jover R.. ${ }^{1}$, Paniagua Iglesias P.1, Miralles Bagan J.1, Parera Ruiz A. ${ }^{1}$, Popova E.2, Moral García M.V.1 Department of Anaesthesiology1, Department of Epidemiology². Universitary Hospital Santa Creu i Sant Pau, Barcelona, Spain}

\section{Background}

If a patient on dabigatran treatment needs an urgent surgery, hemodialysis has been shown to be a useful tool to decrease dabigatran plasma levels due to his low plasma protein binding.

\section{Case report}

A 71-year-old male patient, with non-valvular atrial fibrillation anticoagulated with dabigatran $110 \mathrm{mg} / 12 \mathrm{~h}$, chronic kidney disease stage III and multivessel coronary artery disease waiting for coronary artery bypass grafting (CABG) suffered a sudden cardiac arrest.

From admission, continuous elongated times on clotting assays TT and aPTT was detected along 7 days. We performed diluted thrombin time (Hemoclot assay $\left.{ }^{\circledR}\right)$ (Graph1) the seventh day and detected dabigatran plasma levels.

As CAGB couldn't be delayed we performed an extended intermittent hemodialysis for 8 hours with improvement in Hemoclot $\circledast$ assay values (Graph1). A slight rebound in dabigatran's Hemoclot assay ${ }^{\circledR}$ concentration was observed the next day probably due to his 60-70 liters of volume of distribution but surgery was performed without bleeding complications and the patient could be discharged ten days later.

\section{Discusion}

The reason of persistently increased plasma levels of dabigatran in our patient was his exacerbated chronic renal failure with GFR $<30 \mathrm{ml} / \mathrm{min}$. PCC or FVIla were discarded by the increased thrombotic risk in a patient with recent ischemia and Idarucizumab was not available.

\section{Learning points}

Dialysis due to dabigatran's pharmacokinetic profile with low plasma protein binding is a good therapeutic option, wich enables clearing plasma dabigatran concentration and improve patient's hemostasis when urgent surgery is required.

\section{References}

1. Wilson JA. An evaluation of oral dabigatran etexilate pharmacokinetics and pharmacodynamics in hemodialysis. J Clin Pharmacol. 2014 Aug;54(8):901-9.

2. Davis EM. Strategies for urgent reversal of target-specific oral anticoagulants. Hosp Pract (1995). 2014 Dec;42(5):108-25. 